\title{
Thermal Images in the Assessment of Post-Herpetic Neuralgia: A Case Study
}

\author{
Rafael Alves de Souza1 ${ }^{1}$, Franciele De Meneck², Bruno Cavellucci ${ }^{3}$, Luciane Fachin Balbinot ${ }^{4}$, \\ Marcos Leal Brioschi ${ }^{5}$ and Eduardo Borba Neves ${ }^{6 *}$ \\ ${ }^{1}$ Fisioterapeuta Especialista em Termologia Médica, Faculdade de Medicina, São Paulo-SP, Brazil \\ ${ }^{2}$ Mestre em Medicina Translacional, Faculdade de Medicina, São Paulo-SP, Brazil \\ ${ }^{3}$ Médico Especialista em Dor, Faculdade de Medicina, São Paulo-SP, Brazil \\ ${ }^{4}$ Doutora em Ciências Biológicas (Neurociências), Faculdade de Medicina, São Paulo-SP, Brazil \\ ${ }^{5}$ Doutor em Engenharia Mecânica, Faculdade de Medicina, São Paulo-SP, Brazil \\ ${ }^{6}$ Doutor em Engenharia Biomédica, Programa de Pós-graduação em Engenharia Biomédica, Curitiba-PR, Brazil \\ *Corresponding author: Eduardo Borba Neves, Universidade Tecnológica Federal do Paraná (UTFPR), Curitiba-PR, Brazil
}

\section{ARTICLE INFO}

Received:

Published: 慧 July 06, 2020

Citation: Souza RA, De Meneck F, Cavellucci B, Balbinot LF, Brioschi ML, Neves EB. Thermal Images in the Assessment of PostHerpetic Neuralgia: A Case Study. Biomed J Sci \& Tech Res 28(4)- 2020. BJSTR. MS.ID.004685.

Keywords: Herpes; Herpes Zoster; Neuropathic Diseases; Thermography

\section{ABSTRACT}

Post-herpetic neuralgia is due to an acute painful viral infection resulting from endogenous activation of the varicella virus. The thermal Image (or thermography) is a tool applicable to the diagnosis and clinical monitoring of neuropathic diseases. In this sense, the aim of this study was to present a case of post-herpetic neuralgia assessed and with its therapeutic approach monitored by thermal images. A Female patient, 11 years old, EVA 9 for 1 year and 4 months on the right flank, paravertebral and intercostal region between the 9th and 11th ribs, without previous trauma, without a closed nosological diagnosis, was assessed with thermal images in March (before intervention) and October (after intervention) 2019, with the measurement of the maximum and minimum temperatures of the demarcated areas. Results shoes that in March 2019 (before intervention), it was found asymmetrical intercostal hot spot between $9^{\text {th }}-11^{\text {th }}$ ribs with the maximum thermal difference $(\Delta \mathrm{T})$ of $0.9^{\circ} \mathrm{C}$, in comparison to the contralateral flank.In the postero anterior image, a hyper-radiant signal was found with a thermal difference $(\Delta \mathrm{T})$ of $0.7^{\circ} \mathrm{C}$, compared to the contralateral flank. Seven months after the start of treatment (October 2019), the right intercostal region showed a maximum thermal difference $(\Delta \mathrm{T})$ of $0.4^{\circ} \mathrm{C}$, compared to the contra lateral flank. In the dorsal region, there was a thermal difference $(\Delta \mathrm{T})$ of $0.2^{\circ} \mathrm{C}$. It can be concluded that thermal images are useful to the formation of the diagnostic hypothesis and assessment of the clinical evolution of the patient with neuropathic pain.

\section{Introduction}

Post-herpetic neuralgia (PHN) is due to an acute painful viral infection resulting from endogenous activation of the varicella virus. The patient reports unilateral cervical spinal, dorsal $(50 \%$ of cases) or lumbo sacral radicular pain, it is rarely bilateral, with allodynia [1]. In PHN, concomitantly or hours after the pain, a rash appears on the affected dermatome that persists for two or four weeks. In cases where the rash does not appear, the serological examination can elucidate the diagnosis. Histopathological studies in the acute and subacute phase of herpes zoster showed the presence of inflammatory infiltrates in the ganglion, nerve bundles, and neuronal losses. In general, the pain associated with herpes zoster starts before or at the beginning of the rash and persists for days or weeks until it disappears or becomes permanent [2]. In the early therapeutic approach to herpes zoster or post-herpetic neuralgia, antivirals, tricyclic antidepressants, and non-steroidal or steroidal anti-inflammatory drugs should be administered. In the chronic phase, topical solutions of capsaicin, lidocaine gel, opioids, nerve and / or sympathetic blocks and radiofrequency are used [3]. 
Neuropathic pain is one of the most common forms of pain that affects the peripheral or central nervous system, with consequent interference in sensitive conduction, generating the patient's perception of pain [3]. The fact that PHN is a viral disease that affects the neural tissue, specifically the fine fibers and its nosological diagnosis is difficult through the usual complimentary exams, such as imaging and electro neuromyography. Diagnostic tests have limited application in the clinical management of patients with PHN [1-3]. Thermography (or thermal image) is a tool applicable to the diagnosis and clinical monitoring of neuropathic diseases [4]. Using thermographic images, it is possible to detect and delimit areas of thermal asymmetry and compare them with regions of thermal or tactile hyperalgesia, which do not result in mapping where the problem occurs [5]. Its use as a diagnostic method is based on the fact that different types of processes are manifested by changes in heat production and changes in blood flow patterns in organs and tissues [6-8]. In this sense, the aim of this study was to present a case of post-herpetic neuralgia (PHN) assessed and with its therapeutic approach monitored by thermal images.

\section{Case Presentation}

Female patient, 11 years old, EVA 9 for 1 year and 4 months on the right flank, para vertebral and inter costal region between the 9th and 11th ribs, without previous trauma, without a closed nosological diagnosis.

\section{Assessments}

After a 15-minute acclimatization time in a room with a controlled environment at $23^{\circ} \mathrm{C}$ and $50 \%$ humidity, the thermal images were captured in the months of March (before intervention) and October (after intervention) 2019 with the Flir C2 Education equipment calibrated with emissivity 0,98 and analyzed with FLIR Tools software. The regions of interest (ROIs) were analyzed using the Flir Tools® software (Flir Brasil, Sorocaba, São Paulo, Brazil), with the measurement of the maximum and minimum temperatures of the demarcated areas.

\section{Therapeutic Approach}

The therapeutic approach adopted started with the blockade of the dorsal sensory ganglion in the right limb, at the levels of T8-T11, Shock Wave Therapy with the BTL SWT-6000 Top line equipment (4 applications with intervals of 7-15-21 days respectively; 2500 shots; $1.5-2.0$ Bar, 5-15 Hz) in the referred dorsal ganglia and the antero lateral inter costal region between the 9th and 11th ribs, and electro acupuncture in the same region, with the Ibramed Neurodyn Portable equipment (8 applications of 40 minutes; how often do you have Acupuncture).

\section{Results of Thermal Images}

In the thermal images taken in March 2019 (before intervention), It was found asymmetrical intercostal hot spot between $9^{\text {th }}-11^{\text {th }}$ ribs with the maximum thermal difference $(\Delta \mathrm{T})$ of $0.9^{\circ} \mathrm{C}$, in comparison to the contra lateral flank (Figure 1a). In the postero anterior image, a hyper-radiant signal was found in a downward spiral band from the region of the thoracic spine towards the ribs with a thermal difference $(\Delta \mathrm{T})$ of $0.7^{\circ} \mathrm{C}$, compared to the contra lateral flank, following the anatomical track (Figure 1b). Seven months after the start of treatment (October 2019), the right inter costal region showed a maximum thermal difference $(\Delta \mathrm{T})$ of $0.4^{\circ} \mathrm{C}$ (Figure 2a), compared to the contra lateral flank. In the dorsal region, there was a thermal difference $(\Delta \mathrm{T})$ of $0.2^{\circ} \mathrm{C}$ (Figure 2b), compared to the contra lateral dorsum.

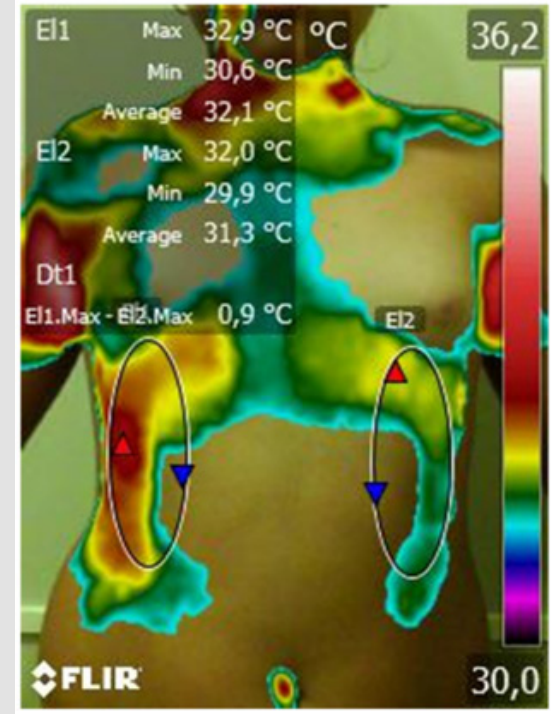

a

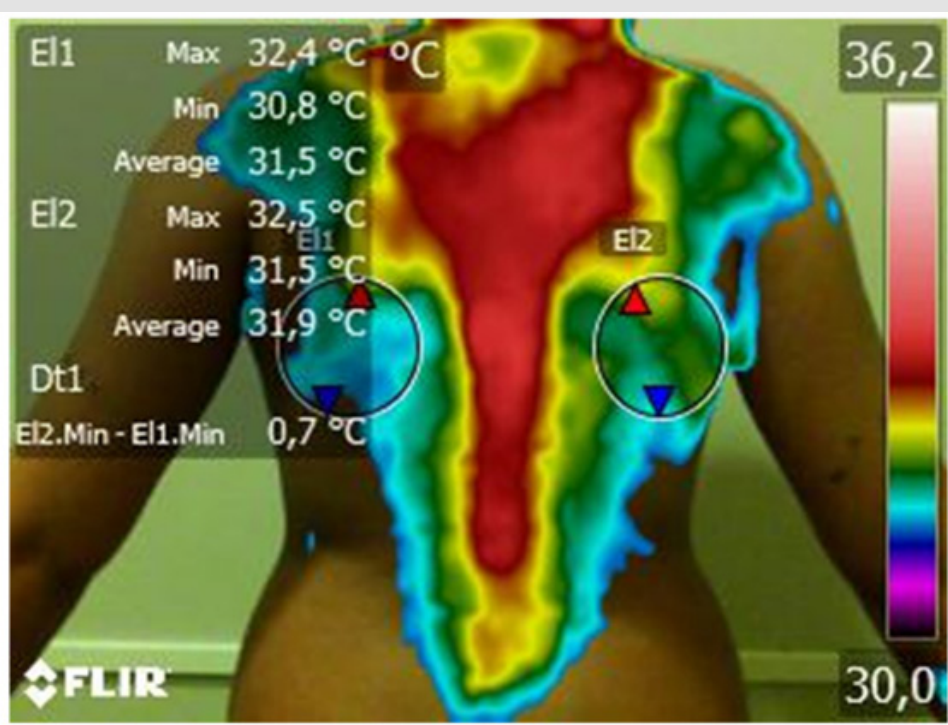

b

Figure 1: a) Thermal image of the frontal view, and

b) Thermal image of the dorsal view, both of a female patient, 11 years old, with post-herpetic neuralgia (PHN), at the baseline of therapeutic Approach, March 2019, Brazil. 


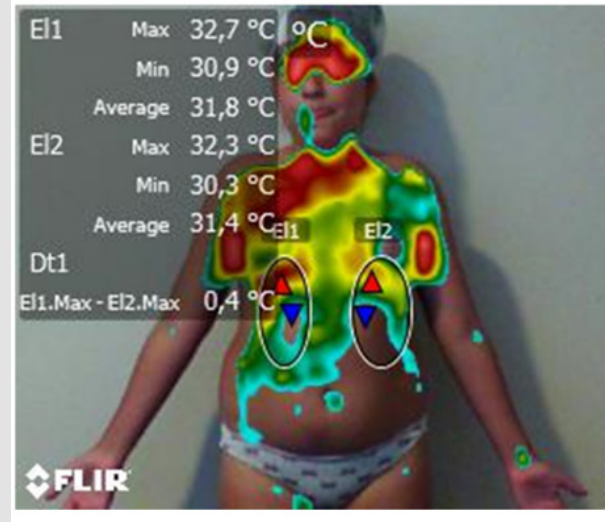

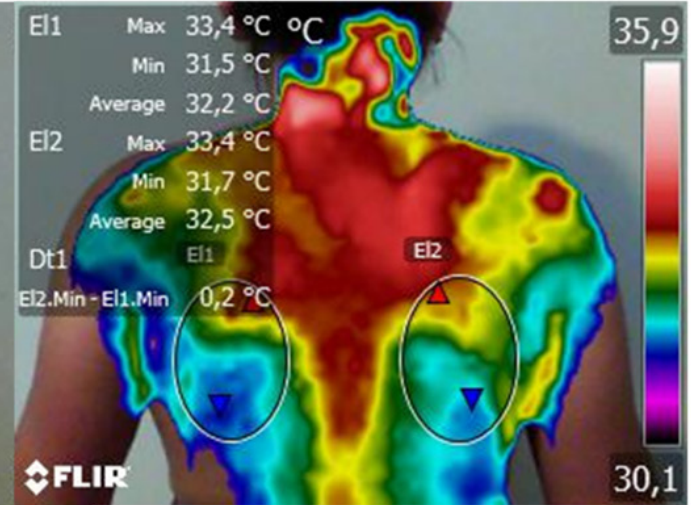

b

Figure 2: a) Thermal image of the frontal view, and

b) Thermal image of the dorsal view, both of a female patient, 11 years old, with post-herpetic neuralgia (PHN), with seven months of therapeutic approach, October 2019, Brazil.

\section{Discussion}

During the study, it is possible to verify the change in the thermal gradient from its initial phase, to the final result of the therapeutic approach. The results observed in this case study are in agreement with the findings of Ko et al. [9], who evaluated 112 individuals (46 men and 66 women) aged 9 to 93 years with herpes zoster, and observed that as the temperature difference between the affected and the contra lateral dermatome $(\Delta T)$ increased, the occurrence of PHN increased significantly. In the same sense, Han et al. [10] evaluated 110 patients diagnosed with acute HZ, with the development of PHN and comorbidities. The temperature differences between the unaffected and affected dermatomes were calculated, identifying differences $>0.6^{\circ} \mathrm{C}$ as abnormal for the mean temperature on the trunk and face. However, in that study, the $\Delta \mathrm{T}$ was not correlated with pain severity, allodynia, disease duration, or development of PHN $(\mathrm{P}>0.05)$.

The pain of neuropathic origin causes changes in skin temperature, through reflex responses of the autonomous nervous system [11]. Thus, the thermography exam emerges as an instrument for assessing post-herpetic neuralgia. Notably, chronic neuropathies present a hypo-radiant signal pattern due to cutaneous vasoconstriction, accompanied by hypothermia. However, patterns of hyperthermia also occur, as is the case with post-herpetic neuralgia [3]. Post-herpetic neuralgia remains one of the most intriguing pains seen in the clinic [12]. Aggressive therapy in the acute phase is more effective, with antiviral treatment, non-steroidal/steroidal anti-inflammatory drugs, tricyclic antidepressants, opioids and eventually nerve blocks [13]. Late alternative treatments, such as shockwave therapy and electro acupuncture when requested, promising responses [14].

\section{Conclusion}

In this study, the compatibility of the thermographic image with the formation of the diagnostic hypothesis and assessment of the clinical evolution of the patient with neuropathic pain became evident, in which it is possible to map the area of pain with relative precision and to monitor its reduction with the treatments proposed. There is a need for much research and investigation regarding the ideal treatment and, mainly, the early diagnostic evaluation of PostHerpetic Neuralgia (PHN), however, Thermography has proved to be a valuable instrument for the patient with this pathology.

\section{References}

1. Johnson R, McElhaney J (2009) Postherpetic neuralgia in the elderly. International journal of clinical practice 63(9): 1386-1391.

2. Thakur R, Kent J, Dworkin R (2010) Herpes zoster and postherpetic neuralgia. Bonica's Management of Pain. In: Fishman SM, Ballantyne JC, Rathmell JP (eds.). Lippincott Williams \& Wilkins pp. 338-55.

3. Mulla SM, Buckley DN, Moulin DE, Couban R, Izhar Z, et al. (2014) Management of chronic neuropathic pain: a protocol for a multiple treatment comparison meta-analysis of randomized controlled trials. BMJ open 4(11): e006112.

4. Neves EB, VilaçaAlves J, Rosa C, Reis VM (2015) Thermography in neurologic practice. The open neurology journal 9: 24-27.

5. Balbinot LF, Canani LH, Robinson CC, Achaval M, Zaro MA (2012) Plantar thermography is useful in the early diagnosis of diabetic neuropathy. Clinics 67(12): 1419-1425.

6. Capitani G, Sehnem E, Rosa C, Matos F, Reis VM, Neves EB (2017) Osgoodschlatter Disease Diagnosis by Algometry and Infrared Thermography. The Open Sports Sciences Journal 13: 223-228.

7. Bandeira F, Neves EB, Moura MAMd, Nohama P (2014) The thermography in support for diagnosis of muscle injury in sport. RevistaBrasileira de Medicina Do Esporte20(1): 59-64.

8. Magas V, de Souza MA, Neves EB, Nohama P (2019) Evaluation of thermal imaging for the diagnosis of repetitive strain injuries of the wrist and hand joints. Research on Biomedical Engineering 35(1): 57-64.

9. Ko E, No Y, Park K, Li K, Seo S, et al. (2016) The clinical significance of infrared thermography for the prediction of postherpetic neuralgia in acute herpes zoster patients. Skin Research and Technology 22(1): 108114 .

10. Han SS, Jung CH, Lee SC, Jung HJ, Kim YH (2010) Does skin temperature difference as measured by infrared thermography within 6 months of acute herpes zoster infection correlate with pain level. Skin Research and Technology 16(2): 198-201. 
11. Rowbotham MC, Fields HL (1989) Post-herpetic neuralgia: the relation of pain complaint, sensory disturbance and skin temperature. Pain 39(2): 129-144.

12. Pak D, Hung JC (2017) Post-Herpetic Neuralgia. Pain medicine: Springer pp. 553-555.

ISSN: 2574-1241

DOI: $10.26717 /$ BJSTR.2020.28.004685

Eduardo Borba Neves. Biomed J Sci \& Tech Res

(C) This work is licensed under Creative

Submission Link: https://biomedres.us/submit-manuscript.php
13. Osuch E, Marais A (2018) An update on available pain medications. South African Family Practice 60(3): 14-20.

14. Wang X, Zhang F, Aixiu X (2016) Therapeutic Observation of Acupuncture with Elongate Needle plus Red Light Radiation for Post-herpetic Neuralgia. Shanghai Journal of Acupuncture and Moxibustion (1): 23-24.

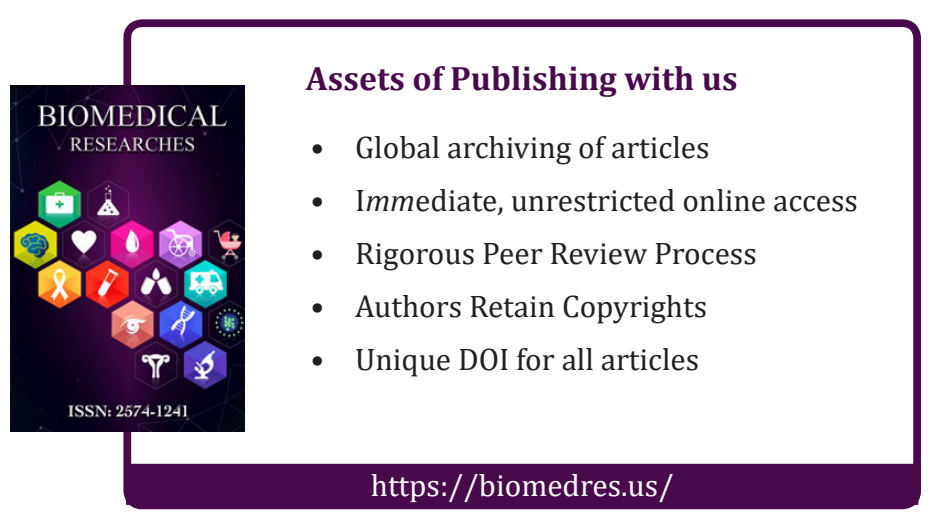

